\title{
Shanghai Ranking's global ranking of academic subjects 2018
}

\author{
Gangan Prathap
}

We see how Indian Higher Educational Institutions (HEIs) have fared in the Shanghai Rankings 2018 for 22 subject areas in engineering and 32 subject areas in four science fields. India has a presence in 19 of the 22 subject areas in engineering, but only 13 of the 32 subject areas in the sciences in which there are institutes globally that meet the required Shanghai Rankings threshold for that area. It has no institution which can be counted at this level of size and excellence in three subjects in the Engineering field: Biomedical Engineering, Marine and Ocean Engineering and Remote Sensing. India's engineering research base is skewed towards hard-core areas like Chemical Engineering, Mechanical Engineering and Electrical and Electronics Engineering. In the four science fields, it has no institution which can be counted in 19 subjects. India's science research base is mainly skewed towards the natural sciences and mathematics areas. Its performance in the medical sciences field is passable and that in the social and life sciences is very dismal.

Keywords: Engineering, research performance, sciences, second-order indicators, Shanghai Rankings.

SHANGHAI Ranking's Global Ranking of Academic Subjects 2018 was released on Tuesday, 17 July 2018 at Shanghai, People's Republic of China by Shanghai Ranking Consultancy. Since 2009, Shanghai Ranking Consultancy (SRC) has published the Academic Ranking of World Universities (ARWU) by academic subjects. The 2018 release contains rankings in 54 subjects across Natural Sciences, Engineering, Life Sciences, Medical Sciences, and Social Sciences. More than 1600 universities from 83 countries and regions appear a total of 18,407 times on the league table. Universities from the United States appear 4661 times, followed by Chinese universities (2171 times) and universities from the United Kingdom (1487 times). University of Michigan-Ann Arbor, University of British Columbia and the University of New South Wales are presented on the league table in 52 subjects, more than any other universities. The engineering rankings are available for twenty-two engineering subjects (the list is shown in Table 1). Across four major science fields: Natural Sciences, Life Sciences, Medical Sciences, and Social Sciences, there are 32 subjects (the list is shown in Table 2).

\section{Methodology}

Shanghai Ranking Consultancy uses a transparent methodology and third-party data. Ranking indicators include

\footnotetext{
Gangan Prathap is in the A P J Abdul Kalam Technological University, Thiruvananthapuram 695 016, India.

e-mail: gangan_prathap@hotmail.com
}

those measures of research productivity, research quality, extent of international collaboration, research with top quality and the highest academic recognitions. The bibliometric data are from Web of Science and InCites database produced by Clarivate Analytics. The ranking indicators are:

PUB The number of papers authored by an institution in an academic subject.

CNCI Category Normalized Citation Impact from InCites to measure average impact of papers authored by an institution in an academic subject.

IC The percentage of internationally co-authored papers authored by an institution in an academic subject.

TOP The number of papers published in top journals and conferences in an academic subject.

AWARD The total number of staff of an institution winning a significant award in an academic subject.

SRC uses a weighting system that allocates different weights for different subjects. For each indicator, scores for institutions are calculated as a percentage of the top scoring institution, then the square root of the percentage is multiplied by the allocated weight. A final score is arrived by adding scores for all indicators and the final score is ranked in descending order. We shall call these the SR ranks. In the present analysis, we shall focus on the research performance aspect of the Indian institutions 
GENERAL ARTICLE

Table 1. Twenty two subject areas in the engineering field and the no. 1 universities from the SR rankings and the $X$-ranking protocol respectively

\begin{tabular}{|c|c|c|c|}
\hline Field & Subject & SR no. 1 & $X$-rank no. 1 \\
\hline \multirow[t]{22}{*}{ Engineering } & Aerospace Engineering & Beihang University & Georgia Institute of Technology \\
\hline & Automation and Control & University of Illinois at Urbana-Champaign & University of California, Santa Barbara \\
\hline & Biomedical Engineering & Harvard University & Fudan University \\
\hline & Biotechnology & Harvard University & Harvard University \\
\hline & Chemical Engineering & Massachusetts Institute of Technology & Beijing University of Chemical Technology \\
\hline & Civil Engineering & Tongji University & $\begin{array}{l}\text { University at Buffalo, the State University of } \\
\text { New York }\end{array}$ \\
\hline & Computer Science and Engineering & Massachusetts Institute of Technology & Massachusetts Institute of Technology \\
\hline & Electrical and Electronic Engineering & Massachusetts Institute of Technology & University of Pennsylvania \\
\hline & Energy Science and Engineering & Nanyang Technological University & Northwestern University \\
\hline & $\begin{array}{l}\text { Environmental Science and } \\
\text { Engineering }\end{array}$ & Stanford University & Swiss Federal Institute of Technology Zurich \\
\hline & Food Science and Technology & University of Wageningen & University of Wageningen \\
\hline & $\begin{array}{l}\text { Instruments Science and } \\
\text { Technology }\end{array}$ & Harbin Institute of Technology & Harbin Institute of Technology \\
\hline & Marine/Ocean Engineering & Shanghai Jiao Tong University & Shanghai Jiao Tong University \\
\hline & Materials Science and Engineering & Massachusetts Institute of Technology & Stanford University \\
\hline & Mechanical Engineering & University of Cambridge & University of Cambridge \\
\hline & Metallurgical Engineering & $\begin{array}{l}\text { University of Science and Technology } \\
\text { Beijing }\end{array}$ & Pohang University of Science and Technology \\
\hline & Mining and Mineral Engineering & The University of Queensland & The University of Queensland \\
\hline & Nanoscience and Nanotechnology & Nanyang Technological University & Massachusetts Institute of Technology \\
\hline & Remote Sensing & Wuhan University & California Institute of Technology \\
\hline & Telecommunication Engineering & Tsinghua University & Tsinghua University \\
\hline & $\begin{array}{l}\text { Transportation Science and } \\
\text { Technology }\end{array}$ & Beijing Jiaotong University & Tsinghua University \\
\hline & Water Resources & University of Arizona & Flinders University \\
\hline
\end{tabular}

in the Shanghai Rankings for engineering. PUB (as a zeroth-order size-dependent measure of quantity of output) and TOP (as a measure of quality or excellence of output) allows us to compute $X=\mathrm{TOP}^{2} / \mathrm{PUB}$ as a secondorder composite indicator of performance ${ }^{1}$.

We shall re-rank the institutions in descending order and call these the $X$-ranks. Note that if an institution has both TOP and PUB equal to $100, X$ is 100 . However, this does not mean that $X$ cannot exceed 100 ! For example, in Aerospace Engineering, Georgia Institute of Technology which has an SRC rank of 2 has a $\mathrm{PUB}=60.6$ and a TOP $=100.00$ yielding an $X=165.02$. It has then an $X$ rank of 1 . Beihang University was ranked no. 1 in the Shanghai Rankings for Aerospace Engineering. However, with $\mathrm{PUB}=100$ and TOP $=75.80$, its $X=57.46$ moves it to the 5th rank. For an example from the Social Sciences field, in Law, Yale University which has an SRC rank of 2 has a PUB $=78.2$ and a TOP $=100.00$ yielding an $X=127.88$. It has then an $X$-rank of 1 . Harvard University was ranked no. 1 in the Shanghai Rankings for Law. However, with $\mathrm{PUB}=100$ and $\mathrm{TOP}=90.60$, its $X=$ 82.08 moves it to the $2 \mathrm{nd}$ rank, behind Yale. This is not surprising as the second-order indicator rewards high quality and punishes poor quality because of the quadratic term assigned to the quality proxy ${ }^{1}$. Tables 1 and 2 show what happens to the no. 1 position when the $X$ ranks are used instead of the SR-ranks for the 22 subjects in the engineering field and all the 32 subjects in the sciences fields. We think that this gives a better picture than the weighting scheme used by SRC if our attention is to be restricted to research performance alone.

\section{Results and discussions}

Universities from India have been ranked by SRC in 22 engineering subjects and now assigned $X$-ranks as indicated above. India has a presence in 19 of the 22 subject areas in which there are institutes globally that meet the required threshold for that area. It has no institution which can be counted at this level of size and excellence in three subjects: Biomedical Engineering, Marine and Ocean Engineering and Remote Sensing. India's engineering research base is skewed towards hard-core areas, e.g. Chemical Engineering (19 institutions), Electrical and Electronics Engineering (12) and Mechanical Engineering (10). In Chemical Engineering there are 7 institutions in the top $100 X$-ranks. Also, many non-IIX institutions appear in this list: Institute of Chemical Technology, Mumbai; Jadavpur University; National Institute Technology Tiruchirappalli; Sardar Vallabhbhai National Institute of Technology; Aligarh Muslim University; Banaras Hindu University; Vellore Institute of Technology; University of Calcutta; and Thapar University. IISc's 43rd rank in the $X$-ranks for Aerospace Engineering is also commendable. The concerted effort on 
GENERAL ARTICLE

Table 2. Thirty two subject areas in the four science fields and the no. 1 universities from the SR rankings and the $X$-ranking protocol respectively

\begin{tabular}{|c|c|c|c|}
\hline Field & Subject & SR no. 1 & $X$-rank no. 1 \\
\hline \multirow[t]{8}{*}{ Natural Sciences } & Atmospheric Science & University of Colorado at Boulder & $\begin{array}{l}\text { University of Versailles Saint-Quentin- } \\
\text { en-Yvelines }\end{array}$ \\
\hline & Chemistry & University of California, Berkeley & University of California, Berkeley \\
\hline & Earth Sciences & University of Colorado at Boulder & California Institute of Technology \\
\hline & Ecology & University of Montpellier & University of Exeter \\
\hline & Geography & University of Oxford & Utrecht University \\
\hline & Mathematics & Princeton University & Princeton University \\
\hline & Oceanography & University of Washington & University of Washington \\
\hline & Physics & $\begin{array}{l}\text { Massachusetts Institute of } \\
\text { Technology }\end{array}$ & University of Chicago \\
\hline \multirow[t]{4}{*}{ Life Sciences } & Agricultural Sciences & University of Wageningen & University of Wageningen \\
\hline & Biological Sciences & Harvard University & Harvard University \\
\hline & Human Biological Sciences & Harvard University & Harvard University \\
\hline & Veterinary Sciences & Ghent University & Ghent University \\
\hline \multirow[t]{6}{*}{ Medical Sciences } & Clinical Medicine & Harvard University & Harvard University \\
\hline & Dentistry and Oral Sciences & University of Michigan-Ann Arbor & University of Michigan-Ann Arbor \\
\hline & Medical Technology & Harvard University & Harvard University \\
\hline & Nursing & University of Pennsylvania & King's College London \\
\hline & Pharmacy and Pharmaceutical Sciences & Harvard University & University of California, San Diego \\
\hline & Public Health & Harvard University & Pompeu Fabra University \\
\hline \multirow[t]{14}{*}{ Social Sciences } & Business Administration & University of Pennsylvania & Northwestern University \\
\hline & Communication & $\begin{array}{l}\text { The Ohio State University - } \\
\text { Columbus }\end{array}$ & The Ohio State University - Columbus \\
\hline & Economics & Harvard University & University of Chicago \\
\hline & Education & Harvard University & University of California, Irvine \\
\hline & Finance & New York University & University of Chicago \\
\hline & Hospitality and Tourism Management & $\begin{array}{l}\text { The Hong Kong Polytechnic } \\
\text { University }\end{array}$ & The Hong Kong Polytechnic University \\
\hline & Law & Harvard University & Yale University \\
\hline & Library and Information Science & Harvard University & Harvard University \\
\hline & Management & Harvard University & INSEAD \\
\hline & Political Sciences & Harvard University & Yale University \\
\hline & Psychology & Harvard University & Stanford University \\
\hline & Public Administration & Erasmus University Rotterdam & Aarhus University \\
\hline & Sociology & Harvard University & Stanford University \\
\hline & Statistics & Harvard University & Princeton University \\
\hline
\end{tabular}

Nanoscience and Nanotechnology seems to be paying off slowly; there are 10 institutions, but the ranks are modest (none in the top 200).

Table 3 is a university-wise tabulation of the engineering subjects in which 24 Indian universities have been ranked by SRC. The IIT at Kharagpur shows up in 16 areas and the Indian Institute of Science appears in 13 areas. The IITs at Delhi (12), Madras (12), Bombay (11), Roorkee (10) also appear to have performed creditably. Anna University (10) and Jadavpur University (7) have also done well considering that they are state universities with vastly limited funding. The National Institutes of Technology at Rourkela, Tiruchirappalli and Surat with 1 appearance each are in this list. Thapar University (3) and Vellore Institute of Technology (1) are the only private universities that make it to this class.

These lists are somewhat different from that which have appeared recently in these pages ${ }^{2}$, where a different methodology has been used. Although the WoS schema has 225 subject categories, Jaya Kumar and Pandit ${ }^{2}$ chose a coarser categorization using 22 categories reclassified into 9 topics. However, the IISc and IITs appear most frequently there as well.

Tables 4-7 show the presence of Indian universities in the four major science fields. In the Life Sciences no university from India has made the cut. India has a presence in only 13 of the 32 subject areas in which there are institutes globally that meet the required threshold for that area. It has no institution which can be counted at this level of size and excellence in 19 subjects. India's science research base is mainly skewed towards the natural sciences and mathematics areas. Here, it has no presence in Geography and Oceanography. Only Panjab University has managed to get into the Top 100 when $X$ ranks are considered. India's performance in the medical sciences field is passable. Of the six areas in this field, it has no presence in Dentistry and Oral Sciences, Medical Technology, Nursing and Public Health. In Clinical Medicine only one institution makes the grade. In the Social Sciences field, out of 14 subject areas, it does not have a 
GENERAL ARTICLE

Table 3. Engineering subjects in which Indian universities have been ranked by SRC

\begin{tabular}{|c|c|c|c|}
\hline Institution & Subject & $X$-rank & SR-rank \\
\hline Aligarh Muslim University & Chemical Engineering & 234 & $301-400$ \\
\hline \multirow[t]{10}{*}{ Anna University } & Automation and Control & 186 & $151-200$ \\
\hline & Biotechnology & 372 & $301-400$ \\
\hline & Chemical Engineering & 284 & $101-150$ \\
\hline & Civil Engineering & 195 & $201-300$ \\
\hline & Energy Science and Engineering & 373 & $201-300$ \\
\hline & Environmental Science and Engineering & 481 & $401-500$ \\
\hline & Materials Science and Engineering & 386 & $301-400$ \\
\hline & Mechanical Engineering & 300 & $201-300$ \\
\hline & Metallurgical Engineering & 197 & $151-200$ \\
\hline & Nanoscience and Nanotechnology & 391 & $301-400$ \\
\hline \multirow[t]{2}{*}{ Banaras Hindu University } & Biotechnology & 385 & $401-500$ \\
\hline & Chemical Engineering & 238 & $301-400$ \\
\hline Guru Nanak Dev University & Food Science and Technology & 288 & $151-200$ \\
\hline \multirow[t]{13}{*}{ Indian Institute of Science } & Aerospace Engineering & 43 & 39 \\
\hline & Chemical Engineering & 72 & $201-300$ \\
\hline & Civil Engineering & 249 & $201-300$ \\
\hline & Computer Science and Engineering & 163 & $301-400$ \\
\hline & Electrical and Electronics Engineering & 257 & $201-300$ \\
\hline & Energy Science and Engineering & 227 & $301-400$ \\
\hline & Instruments Science and Technology & 137 & $151-200$ \\
\hline & Materials Science and Engineering & 374 & $201-300$ \\
\hline & Mechanical Engineering & 87 & $101-150$ \\
\hline & Metallurgical Engineering & 32 & 28 \\
\hline & Nanoscience and Nanotechnology & 285 & $201-300$ \\
\hline & Telecommunication Engineering & 57 & $151-200$ \\
\hline & Water Resources & 109 & $151-200$ \\
\hline \multirow[t]{3}{*}{ Indian Institute of Technology (Indian School of Mines), Dhanbad } & Chemical Engineering & 217 & $301-400$ \\
\hline & Electrical and Electronics Engineering & 429 & $401-500$ \\
\hline & Mining and Mineral Engineering & 55 & $51-75$ \\
\hline \multirow[t]{11}{*}{ Indian Institute of Technology Bombay } & Automation and Control & 49 & $76-100$ \\
\hline & Chemical Engineering & 25 & $151-200$ \\
\hline & Civil Engineering & 192 & $201-300$ \\
\hline & Electrical and Electronics Engineering & 248 & $201-300$ \\
\hline & Energy Science and Engineering & 272 & $301-400$ \\
\hline & Environmental Science and Engineering & 362 & $401-500$ \\
\hline & Instruments Science and Technology & 122 & $101-150$ \\
\hline & Materials Science and Engineering & 442 & $401-500$ \\
\hline & Mechanical Engineering & 109 & $151-200$ \\
\hline & Metallurgical Engineering & 75 & $101-150$ \\
\hline & Nanoscience and Nanotechnology & 363 & $301-400$ \\
\hline \multirow[t]{12}{*}{ Indian Institute of Technology Delhi } & Biotechnology & 274 & $301-400$ \\
\hline & Chemical Engineering & 165 & $201-300$ \\
\hline & Civil Engineering & 81 & $151-200$ \\
\hline & Computer Science and Engineering & 262 & $301-400$ \\
\hline & Electrical and Electronics Engineering & 255 & $151-200$ \\
\hline & Energy Science and Engineering & 390 & $301-400$ \\
\hline & Environmental Science and Engineering & 426 & $401-500$ \\
\hline & Instruments Science and Technology & 82 & $151-200$ \\
\hline & Materials Science and Engineering & 331 & $301-400$ \\
\hline & Mechanical Engineering & 215 & $151-200$ \\
\hline & Nanoscience and Nanotechnology & 386 & $301-400$ \\
\hline & Telecommunication Engineering & 98 & $101-150$ \\
\hline \multirow[t]{6}{*}{ Indian Institute of Technology Guwahati } & Biotechnology & 324 & $401-500$ \\
\hline & Chemical Engineering & 81 & $151-200$ \\
\hline & Electrical and Electronics Engineering & 430 & $401-500$ \\
\hline & Energy Science and Engineering & 437 & $401-500$ \\
\hline & Mechanical Engineering & 168 & $201-300$ \\
\hline & Nanoscience and Nanotechnology & 379 & $301-400$ \\
\hline \multirow[t]{7}{*}{ Indian Institute of Technology Kanpur } & Chemical Engineering & 37 & $201-300$ \\
\hline & Electrical and Electronics Engineering & 228 & $201-300$ \\
\hline & Energy Science and Engineering & 438 & $401-500$ \\
\hline & Materials Science and Engineering & 322 & $301-400$ \\
\hline & Mechanical Engineering & 103 & $101-150$ \\
\hline & Metallurgical Engineering & 96 & $101-150$ \\
\hline & Nanoscience and Nanotechnology & 387 & $301-400$ \\
\hline
\end{tabular}


GENERAL ARTICLE

Table 3. (Contd $)$

\begin{tabular}{|c|c|c|c|}
\hline Institution & Subject & $X$-rank & SR-rank \\
\hline \multirow[t]{16}{*}{ Indian Institute of Technology Kharagpur } & Automation and Control & 166 & $151-200$ \\
\hline & Biotechnology & 177 & $301-400$ \\
\hline & Chemical Engineering & 65 & $101-150$ \\
\hline & Civil Engineering & 250 & $201-300$ \\
\hline & Computer Science and Engineering & 444 & $301-400$ \\
\hline & Electrical and Electronics Engineering & 348 & $301-400$ \\
\hline & Energy Science and Engineering & 355 & $301-400$ \\
\hline & Environmental Science and Engineering & 428 & $401-500$ \\
\hline & Instruments Science and Technology & 123 & $201-300$ \\
\hline & Materials Science and Engineering & 394 & $301-400$ \\
\hline & Mechanical Engineering & 142 & $76-100$ \\
\hline & Metallurgical Engineering & 86 & $76-100$ \\
\hline & Mining and Mineral Engineering & 38 & $51-75$ \\
\hline & Nanoscience and Nanotechnology & 365 & $301-400$ \\
\hline & Telecommunication Engineering & 174 & $151-200$ \\
\hline & Water Resources & 117 & $101-150$ \\
\hline \multirow[t]{12}{*}{ Indian Institute of Technology Madras } & Chemical Engineering & 56 & $101-150$ \\
\hline & Civil Engineering & 89 & $151-200$ \\
\hline & Computer Science and Engineering & 158 & $401-500$ \\
\hline & Electrical and Electronics Engineering & 231 & $201-300$ \\
\hline & Energy Science and Engineering & 391 & $301-400$ \\
\hline & Instruments Science and Technology & 169 & $201-300$ \\
\hline & Materials Science and Engineering & 443 & $401-500$ \\
\hline & Mechanical Engineering & 76 & $51-75$ \\
\hline & Metallurgical Engineering & 45 & $51-75$ \\
\hline & Nanoscience and Nanotechnology & 378 & $301-400$ \\
\hline & Telecommunication Engineering & 126 & $151-200$ \\
\hline & Transportation Science and Technology & 179 & $151-200$ \\
\hline \multirow[t]{10}{*}{ Indian Institute of Technology Roorkee } & Chemical Engineering & 210 & $151-200$ \\
\hline & Civil Engineering & 223 & $201-300$ \\
\hline & Electrical and Electronics Engineering & 431 & $401-500$ \\
\hline & Energy Science and Engineering & 349 & $301-400$ \\
\hline & Environmental Science and Engineering & 492 & $401-500$ \\
\hline & Materials Science and Engineering & 444 & $401-500$ \\
\hline & Mechanical Engineering & 251 & $151-200$ \\
\hline & Metallurgical Engineering & 146 & $151-200$ \\
\hline & Nanoscience and Nanotechnology & 392 & $301-400$ \\
\hline & Water Resources & 164 & $151-200$ \\
\hline Indian Statistical Institute & Computer Science and Engineering & 484 & $401-500$ \\
\hline Institute of Chemical Technology, Mumbai & Chemical Engineering & 43 & $76-100$ \\
\hline \multirow[t]{7}{*}{ Jadavpur University } & Automation and Control & 190 & $151-200$ \\
\hline & Chemical Engineering & 177 & $301-400$ \\
\hline & Computer Science and Engineering & 486 & $401-500$ \\
\hline & Electrical and Electronics Engineering & 437 & $401-500$ \\
\hline & Energy Science and Engineering & 441 & $401-500$ \\
\hline & Instruments Science and Technology & 84 & $151-200$ \\
\hline & Mechanical Engineering & 244 & $201-300$ \\
\hline Jawaharlal Nehru University & Biotechnology & 449 & $401-500$ \\
\hline National Institute of Technology Rourkela & Electrical and Electronics Engineering & 450 & $401-500$ \\
\hline National Institute Technology Tiruchirappalli & Chemical Engineering & 209 & $301-400$ \\
\hline Sardar Vallabhbhai National Institute of Technology & Chemical Engineering & 215 & $401-500$ \\
\hline Shivaji University & Materials Science and Engineering & 466 & $401-500$ \\
\hline \multirow[t]{3}{*}{ Thapar University } & Chemical Engineering & 412 & $401-500$ \\
\hline & Computer Science and Engineering & 493 & $401-500$ \\
\hline & Electrical and Electronics Engineering & 463 & $401-500$ \\
\hline University of Calcutta & Chemical Engineering & 406 & $401-500$ \\
\hline \multirow[t]{2}{*}{ University of Delhi } & Biotechnology & 338 & $301-400$ \\
\hline & Nanoscience and Nanotechnology & 390 & $301-400$ \\
\hline Vellore Institute of Technology & Chemical Engineering & 262 & $301-400$ \\
\hline NA & Biomedical Engineering & NA & NA \\
\hline NA & Marine and Ocean Engineering & NA & NA \\
\hline NA & Remote Sensing & NA & NA \\
\hline
\end{tabular}


GENERAL ARTICLE

Table 4. Number of Indian universities which have been ranked by SRC in Natural Science subjects

\begin{tabular}{|c|c|c|c|c|}
\hline Subject & Institution & $X$-rank & SR-rank & Total SR ranks \\
\hline \multirow[t]{5}{*}{ Atmospheric Science } & Indian Institute of Technology Kanpur & 240 & $301-400$ & 400 \\
\hline & Indian Institute of Science & 280 & $301-400$ & \\
\hline & Indian Institute of Technology Bombay & 312 & $301-400$ & \\
\hline & Banaras Hindu University & 333 & $301-400$ & \\
\hline & Indian Institute of Technology Kharagpur & 347 & $301-400$ & \\
\hline \multirow{5}{*}{ Chemistry } & Indian Institute of Science Education and Research (IISER), Pune & 318 & $401-500$ & \\
\hline & Indian Institute of Technology Bombay & 382 & $301-400$ & \\
\hline & Indian Institute of Technology Kanpur & 411 & $301-400$ & \\
\hline & Indian Institute of Technology Madras & 452 & $401-500$ & \\
\hline & Indian Institute of Technology Kharagpur & 487 & $401-500$ & \\
\hline \multirow[t]{3}{*}{ Earth Sciences } & Indian Institute of Science & 325 & $401-500$ & 500 \\
\hline & Indian Institute of Technology Kharagpur & 400 & $401-500$ & \\
\hline & Indian Institute of Technology Bombay & 465 & $401-500$ & \\
\hline Geography & NA & NA & NA & 200 \\
\hline \multirow[t]{5}{*}{ Mathematics } & Indian Institute of Science & 249 & $301-400$ & 500 \\
\hline & Indian Statistical Institute & 279 & $201-300$ & \\
\hline & Aligarh Muslim University & 379 & $301-400$ & \\
\hline & Anna University & 479 & $301-400$ & \\
\hline & Indian Institute of Technology Roorkee & 480 & $401-500$ & \\
\hline Oceanography & NA & NA & NA & 200 \\
\hline \multirow[t]{5}{*}{ Physics } & Panjab University & 83 & $151-200$ & 500 \\
\hline & Visva Bharati University & 361 & $401-500$ & \\
\hline & Indian Institute of Technology Bombay & 406 & $401-500$ & \\
\hline & Indian Institute of Science & 459 & $401-500$ & \\
\hline & Indian Institute of Science Education and Research (IISER), Kolkata & 474 & $401-500$ & \\
\hline
\end{tabular}

Table 5. No Indian university was ranked by SRC in Life Science subjects

\begin{tabular}{lcccc}
\hline Subject & Institution & $X$-rank & SR-rank & $\begin{array}{c}\text { Total } \\
\text { SR ranks }\end{array}$ \\
\hline Agricultural Sciences & NA & NA & NA & 500 \\
Biological Sciences & NA & NA & NA & 500 \\
Human Biological Sciences & NA & NA & NA & 500 \\
Veterinary Sciences & NA & NA & NA & 300 \\
\hline
\end{tabular}

single institution in 10 areas: Business Administration, Communication, Education, Hospitality and Tourism Management, Finance, Law, Library and Information Science, Psychology, Public Administration, and Sociology.

These lists are somewhat different from that which have appeared recently in these pages ${ }^{2}$, where a different methodology for ranking, based on citation count alone, has been used. Although the WoS schema has 225 subject categories, a coarser categorization using 22 categories reclassified into 9 topics was chosen ${ }^{2}$. Taken together, ref. 2 and the present analysis give a good view of the research landscape in India vis-à-vis the rest of the world.

Taking the engineering and science lists together, we find that a total of 33 unique HEIs have appeared 164 times. Considering that more than 1600 universities from
83 countries and regions have appeared a total of 18,407 times on the global SRC league table, India's share of HEIs in the SRC rankings is about $2.1 \%$ and its share of appearances is only $0.89 \%$. There are very few appearances in the Top $100 X$-ranks and these are mainly in engineering (24 out of 25, the sole exception being Panjab University in Physics). Chemical Engineering appears seven times in this list of 25 (see Table 3 to identify the list of institutions) and is arguably the best performing discipline in India.

\section{Conclusions}

The SRC Subject Rankings 2018 has been recently released. We use the data to see how Indian HEIs have fared in the engineering and sciences fields. India has a presence in 19 of the 22 subject areas in which there are institutes globally that meet the required threshold for that area. The Indian Institute of Science and the older Indian Institutes of Technology stand out among Indian counterparts but are far below global competitors. In three subjects: Biomedical Engineering, Marine and Ocean Engineering and Remote Sensing, it has no institution which can be counted at this level of size and excellence. India's engineering research base is skewed towards hard-core areas like Chemical Engineering, 
GENERAL ARTICLE

Table 6. Number of Indian universities which have been ranked by SRC in Medical Science subjects

\begin{tabular}{|c|c|c|c|c|}
\hline Subject & Institution & $X$-rank & SR-rank & Total SR ranks \\
\hline Clinical Medicine & All India Institute of Medical Sciences & 111 & $301-400$ & 500 \\
\hline Dentistry and Oral Sciences & NA & NA & NA & 300 \\
\hline Medical Technology & NA & NA & NA & 300 \\
\hline Nursing & NA & NA & NA & 300 \\
\hline \multirow[t]{5}{*}{ Pharmacy and Pharmaceutical Sciences } & Jamia Hamdard University & 167 & $201-300$ & 500 \\
\hline & Panjab University & 314 & $401-500$ & \\
\hline & University of Delhi & 354 & $401-500$ & \\
\hline & Aligarh Muslim University & 458 & $301-400$ & \\
\hline & Indian Institute of Science & 489 & $401-500$ & \\
\hline Public Health & All India Institute of Medical Sciences & 214 & 46 & 500 \\
\hline
\end{tabular}

Table 7. Number of Indian universities which have been ranked by SRC in Social Science subjects

\begin{tabular}{|c|c|c|c|c|}
\hline Subject & Institution & $X$-rank & SR-rank & Total SR ranks \\
\hline Business Administration & NA & NA & NA & 400 \\
\hline Communication & NA & NA & NA & 300 \\
\hline Economics & Indian Statistical Institute & 267 & $301-400$ & 500 \\
\hline Education & NA & NA & NA & 500 \\
\hline Hospitality and Tourism Management & NA & NA & NA & 200 \\
\hline Finance & NA & NA & NA & 200 \\
\hline Law & NA & NA & NA & 200 \\
\hline Library and Information Science & NA & NA & NA & 100 \\
\hline \multirow[t]{3}{*}{ Management } & Indian Institute of Management, Bangalore & 142 & $301-400$ & 500 \\
\hline & Indian Institute of Management, Ahmedabad & 216 & $401-500$ & \\
\hline & Indian Institute of Technology, Kharagpur & 478 & $401-500$ & \\
\hline Political Sciences & Jawaharlal Nehru University & 284 & $301-400$ & 400 \\
\hline Psychology & NA & NA & NA & 500 \\
\hline Public Administration & NA & NA & NA & 200 \\
\hline Sociology & NA & NA & NA & 200 \\
\hline Statistics & Indian Statistical Institute & 116 & $51-75$ & 200 \\
\hline
\end{tabular}

Mechanical Engineering and Electrical and Electronics Engineering.

In the four main science fields: Natural Sciences, Life Sciences, Medical Sciences, and Social Sciences, India has a presence in only 13 of the 32 subject areas in which there are institutes that meet the SRC standards of excellence. It has no institution in 19 subjects. India's science research base is mainly skewed towards the Natural Sciences and Mathematics areas. Its performance in the medical sciences field is passable and that in the Social and Life Sciences is very dismal. It therefore has a long way to go to meet global standards.

1. Prathap, G., The Energy-Exergy-Entropy (or EEE) sequences in bibliometric assessment. Scientometrics, 2011, 87(3), 515-524.

2. Jaya Kumar, A. and Pandit, R., Science and engineering research in India (1985-2016): insights from two scientometric databases. Curr. Sci., 2018, 115(3), 399-409.

Received 10 August 2018; revised accepted 22 October 2018

doi: $10.18520 / \mathrm{cs} / \mathrm{v} 116 / \mathrm{i} 2 / 232-238$ 